the hospital service, and between all the services, to avoid the departmentalizing of medicine which prevents doctors from seeing the patient as a 'whole person' rather than as a 'case'. 'Fifthly, there must be encouragement of variety and experiment, and, lastly, a preventive and positive outlook on health must be actively encouraged. The text of the booklet is supplemented by a number of diagrams showing the administrative structure of the Service.

$$
\sqrt{ }
$$

Public's View

AFTER a full ye yoperation of the National Health Service, Mast $0^{3}$ servation, on behalf of News Review, has carried (Aut a nation-wide survey to determine the vidts of the general public (Mass Observation Report, July 1949). The evidence collected shows tha, "in the main, those who have used the Service are reasonably satisfied. Three-quarters of the people questioned said they personally made use of some branch of the Service during its first year of exist. ence; 49 per cent had used doctors, 42 per cent dentists and 17 per cent oculists. Among the middle classes there is still apparently a good deal of overlap between private and national service. Some members of the middle classes, for example, go to a panel doctor for treatment for lesser illnesses; but retain the old family doctor on a private basis in case of illness requiring more skilled diagnosis. Three-fifths of those who have had experience of the National Health Service feel that its introduction has benefited them, and about a quarter that the Service has hindered or inconvenienced them. People under forty years of age are more enthusiastic about the new Service than the older generation. The most common reason for praising the Service is that it saves money. The major criticism, which comes from opponents and supporters of the National Health Service, is of the slowness and waiting now involved -weeks of waiting for a dentist's appointment, hours of waiting outside the doctor's surgery, months of waiting for spectacles. Although opinions on the wisdom of the National Health Service differ considerably, there is almost complete unanimity that the attention given to patients has not suffered in any way. It

\section{Cocoa Industry in Jamaica}

IN Extension Nircular No. 7 (Department of Agriculture, Jampa), J. Wright discusses "The Resuscitation the Cocoa Industry in Jamaica". Good cocpa dotuntries are limited, as the crop requires a temperature of not less than $60^{\circ} \mathrm{F}$., a well-distributed tainfll of more than sixty inches, a suitable soil and an adequate population to attend to its carixation. The bulk of the world's cocoa is produced in ost Africa and Brazil; but since output has fallen so heavily in the former area owing to the ravages of insect pests and virus disease, new sources of production must be found. In times past, Jamaica had quite a thriving cocoa industry which was superseded by the more lucrative banana crop. Large tracts of land, however, which would be suitable for cocoa, still exist, and in view of the present-day troubles with banana disease, the re-introduction of the cocoa industry would seem very desirable; the more so as, with a properly planned economy, the two crops should fit in well together. Bananas form a good nurse crop and provide the necessary shade for cocoa, while cocoa plus shade would check soil erosion on steep lands. Good quality cocoa of the Criollo and Trinitario types are suggested as most suited to the climate, and emphasis laid on the necessity for marketing a high-grade product if the scheme is to be an economic success.

Acoustic Energy and Stellar Models

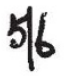

A PAPER by T. Go" entitled "A Thermodynamic Consideratigninonelation to Acoustic Energy in Stellar Model, has recently been published (Mon. Not. RA Astro. Soc., 109, 1; 1949), and in it is discussed the thermodynamic limitations of the gequetion of acoustic energy in stars. Quite recently, M. Schwarzschild and R. S. Richardson suggested that the transfer of energy in stars may, in some circumstances, be accomplished by acoustic wavesa suggestion which Gold does not deny-but his investigation of the subject shows that noise can never become the sole agent of outward energy trans. port. From the thermodynamic point of view, acoustic energy is 'free' energy, because its transfer is not necessarily associated with a transfer of entropy, and this holds whatever may be the spectral distribution of the noise, provided we exclude frequencies so high that the extinction distance becomes short in comparison with the wave-length. It follows that any thermal process which leads to the liberation of acoustic energy is subject to the thermodynamic limitations of a heat engine, and this consideration does not support the views expressed by Richardson and Schwarzschild in dealing with the stellar model of red giants. In this model they suggest that a convective core gives rise to acoustic energy as a result of turbulence, and that this core is surrounded by an isothermal zone in which the outward transport of energy is entirely acoustic. Using the assumed temperatures, $3 \times 10^{7}{ }^{\circ} \mathrm{K}$. and $1.5 \times 10^{7}{ }^{\circ} \mathrm{K}$. at the centre and at the boundary between the noise-producing core and the supposed isothermal zone, Gold shows that at least half the energy would be transported away in heat, and that the surrounding zone could not approach an isothermal condition. The conclusion is that acoustic waves cannot become a major agent of energy transport.

\section{Acoustics of Concert Halls}

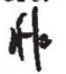

THE problems is acoustical design set by the new London Couñty eouncil South Bank Concert Hall and by the rebuil ing programme for other halls have led to an increased interest in recent attempts to replace the presen statistical and geometrical theories of room a foustics by wave theories (cf. Morse and Bolt, Rev. Mod. Phys., 16, 2; 1944). Arrangements have been made for Prof. R. H. Bolt, director of the Acousties Laboratory, Massachusetts Institute of Technology, to deliver a course of six lectures on this topic under the auspices of the Acoustics Group of the Physical Society, with the general title "Modern Principles of Room Acoustics". The course of lectures will outline the present position reached in the development of the new ideas, and will cover the following ground : classical practice; physical and psycho-acoustic foundations; standing waves; wave statistics and transition regions; free waves and pulse statistics; indications for future practice. The lectures will be given in the Lecture Theatre of the Royal Institution, Albemarle Street, W.1, at 5 p.m., on September 29 and 30 , and on October $3,4,5$ and 7 . A registration fee of $10 s$. $6 d$. (which may be waived in the case of students) will be charged for the course. Further particulars may be obtained from the Joint Honorary Secretaries, Acoustics Group, Physical Society, 1 Lowther Gardens, London, S.W.7. 